Original Research Article

\title{
Knowledge, attitude and practice of research ethics among medical faculty in a teaching hospital
}

\author{
Swetha Munoli ${ }^{1}{ }^{*}$, Niveditha G. ${ }^{1}$, Deepthi R. $^{2}$
}

${ }^{1}$ Department of Pharmacology, 2Department of Community Medicine, ESIC-MC and PGIMSR, Bangalore, Karnataka, India

Received: 27 January 2017

Accepted: 27 February 2017

*Correspondence to:

Dr. Swetha Munoli,

Email:

swethamunoli@gmail.com

Copyright: (C) the author(s), publisher and licensee Medip Academy. This is an openaccess article distributed under the terms of the Creative Commons Attribution NonCommercial License, which permits unrestricted noncommercial use, distribution, and reproduction in any medium, provided the original work is properly cited.

\begin{abstract}
Background: To assess the knowledge, attitudes and practice of medical faculty regarding research ethics and research ethics committees (RECs).

Methods: A cross-sectional, questionnaire-based study was conducted in ESIC medical colleges in Bangalore among faculty using a validated questionnaire. Questions were designed to assess the knowledge, attitudes and practice of medical faculty regarding research ethics and research ethics committees. Statistical analysis was done using descriptive statistics and chi-square tests.

Results: Majority $(76 \%)$ of faculty had not undergone training in research ethics. Less than half of the participants answered correctly to a question on guidelines in research ethics, $60 \%$ responded correctly to question on research involving children. Majority responded correctly to question on role of a research ethics committee and confidentiality, informed consent and to question on composition of Institutional Ethics Committee. 68\% taught that ethical review of research by an ethics committee would delay research. $>90 \%$ were favourable towards research ethics training. Faculty held attitudes regarding certain research ethics practices that were not optimal, $96 \%$ believed that it okay to fabricate data, $68 \%$ taught that if no surrogate is available to give informed consent for vulnerable groups, they could still be included.

Conclusions: We conclude that among the medical faculties participating in our study, there is acceptance of RECs and training in research ethics, while there are knowledge gaps in research ethics guidelines, research involving children. There is need to train researchers and students to make them aware about various aspects of research.
\end{abstract}

Keywords: Attitude, Ethics committee research, Ethics, informed consent, Medical

\section{INTRODUCTION}

Medical research has increased greatly in many developing countries during the recent decade, motivated by the need to improve health in this countries. ${ }^{1}$ since medical research involves human participants; such research needs to be guided by fundamental ethical principles to ensure the protection of their rights and welfare. Furthermore, international standards mandate the review of research by research ethics committees (RECs). ${ }^{2,3}$

Medical ethics has been included in the training curriculum of health professionals in many countries and there has been a growth in the number of ethics specialists and ethics committees. Yet complaints from the public appear to be proliferating. ${ }^{4}$ this may be a reflection of an increased public awareness as well as poor practices within the health care sector. Traditional medical training offers little help in resolving the ethical dilemmas encountered by health care professionals. It has been argued that very few physicians are exposed to training in this important area of medical practice, yet on qualifying health care professionals are expected to know about ethical practice when applying their skills. ${ }^{4}$

\section{METHODS}

A cross-sectional, questionnaire-based study was conducted in ESIC medical colleges in Bangalore among faculty using a validated questionnaire. ${ }^{5}$ The first part collected demographic information of the participants: 
gender, academic position, number of research publications, and prior training in research ethics).The second part of the survey assessed the participant's knowledge in research ethics. The third part of the survey assessed respondent's attitudes regarding research ethics. Respondents were required to choose from a 5-point Likert scale ranging from 1 to 5 (1-strongly agree, 2agree, 3-not sure, 4-disagree and 5-strongly disagree). The fourth part of the questionnaire assessed respondents' attitudes towards certain practices in the conduct of research. Respondents were required to answer "yes", "no". Questionnaire was distributed to 50 participants and 20 min time was given before CME on research ethics.

\section{Statistics}

The data was entered from completed questionnaires into Microsoft Excel and analysed using SPSS. For purposes of analysis, the categories of "strongly agree" and "agree" were collapsed as agree. chi-square tests was used to determine, in bivariate analyses, the association of each of the independent variables (gender, academic position, prior ethics training, number of publication) with each of the main outcome of interest (dependent responses involving knowledge, attitudes and practices).significant level was set at $\mathrm{p}$ value $<0.05$.

\section{RESULTS}

Questionnaire containing 20 questions was distributed to the participants and 20 minutes time was given to answer the questions.

Table 1 shows the demographic data of the faculty, which shows that among the participants female were slightly more than male. Assistant professors were more compared to associate professor and professors. Majority (76\%) of faculty had not undergone training in research ethics and $48 \%$ had $>5$ research publication
Table 1: Demographic information of the participants.

\begin{tabular}{|lll|}
\hline SN & Item & Total \\
\hline 1 & Gender & \\
\hline & Male & $22(44 \%)$ \\
\hline & Female & $28(56 \%)$ \\
\hline 2 & Academic position \\
\hline & Professor & $6(12 \%)$ \\
\hline & Associate professor & $13(26 \%)$ \\
\hline & Assistant professor & $31(62 \%)$ \\
\hline & Number of publication & \\
\cline { 2 - 2 } 3 & 0 & $8(16 \%)$ \\
\cline { 2 - 3 } & $1-2$ & $5(10 \%)$ \\
\cline { 2 - 3 } & $3-5$ & $13(26 \%$ \\
\cline { 2 - 3 } & $>5$ & $24(48 \%)$ \\
\hline 4 & Prior training in ethics & $12(24 \%)$ \\
\hline & Yes & $38(76 \%)$ \\
\hline & No
\end{tabular}

Table 2 shows participants responses to knowledge questions in research ethics. Less than half of the participants answered correctly to a question on guidelines in research ethics, $60 \%$ of participants responded correctly to question on research involving children. $96 \%$ responded correctly to question on role of a research ethics committee and Confidentiality in medical research, $80 \%$ responded correctly to question on Informed consent, $86 \%$ responded correctly to question on Composition of Institutional Ethics Committee, female faculty were significantly ( $p$ value $<0.05$ ) more likely to give correct response for question on Composition of Institutional Ethics Committee.

Female faculty, assistant professor, faculty who had not undergone training and who had published $>5$ research papers responded correctly to all knowledge questions.

Table 2: Knowledge in research ethics.

\begin{tabular}{|c|c|c|c|c|c|c|c|c|c|c|c|c|}
\hline \multirow[t]{2}{*}{ SN } & \multirow[t]{2}{*}{$\begin{array}{l}\text { AGGRE } \\
\operatorname{gate}(\%)\end{array}$} & \multicolumn{2}{|c|}{ Gender (\%) } & \multicolumn{2}{|c|}{ cademic position } & \multicolumn{3}{|c|}{$\begin{array}{l}\text { Prior training in } \\
\text { ethics }\end{array}$} & \multicolumn{4}{|c|}{ Number of publication (mean) } \\
\hline & & Male & Female & Professor & Associate & Assistant & Any & None & $\mathbf{0}$ & $1-2$ & $3-5$ & $>5$ \\
\hline 1 & 44 & 31.82 & 68.18 & 4.55 & 36.36 & 59.09 & 27.27 & 72.73 & 22.73 & 18.18 & 22.73 & 36.36 \\
\hline 2 & 96 & 45.83 & 54.17 & 10.42 & 25.00 & 64.58 & 20.83 & 79.17 & 12.50 & 10.42 & 27. & 50 \\
\hline 3 & 96 & 43.75 & 56.25 & 12.50 & 27.08 & 60.42 & 25 & 75 & 16.67 & 10.42 & 25 & 47.9 \\
\hline 4 & 80 & 40 & 60.00 & 12.50 & 25.00 & 62.50 & 30 & 70 & 17.50 & 7.50 & 25 & 50 \\
\hline 5 & 60 & 36.67 & 63.33 & 13.33 & 26.67 & 60 & 33.33 & 66.67 & 10 & 13.33 & 30 & 46.67 \\
\hline 6 & 86 & 34.88 & $65.12 *$ & 11.63 & 27.91 & 60.47 & 23.26 & 76.74 & 16.28 & 11.63 & 25.58 & 46.51 \\
\hline
\end{tabular}

$* \mathrm{p}$ value $<0.05,1$. Guidelines in research ethics, 2 . Knowledge of the role of a research ethics committee, 3. Confidentiality in medical research, 4. Informed consent, 5. Research involving children, 6. Composition of Institutional Ethics Committee

Table 3 shows attitudes for participants regarding research ethics $>90 \%$ of the participants agreed that there is a need for a research ethics committee in each institution for ethical review of research, the members of a research ethics committee should receive training in research 
bioethics and Research ethics should be taught as a mandatory postgraduate module. $100 \%$ believed that all investigators should have some training in research ethics. $80 \%$ believed that ethical review of research by an EC is not necessary since there are scientific committees. $90 \%$ agreed that ethical review of research is only necessary for international collaborative research. $68 \%$ taught that ethical review of research by an EC would delay research and make it harder for the researcher. Female faculty were significantly ( $\mathrm{p}$ value $<0.05$ ) more likely to believe that ethical review of research by an EC would delay research and make it harder for the researcher.
Table 3 also shows the association between attitude and demographic variables. Female faculty, assistant professor, faculty who had not undergone training and who had published $>5$ research papers were more likely to think that there is a need for a research ethics committee in each institution for ethical review of research, ethical review of research by an EC is not necessary since there are scientific committees, ethical review of research by an EC would delay research and make it harder for the researcher, ethical review of research is only necessary for international collaborative research and believed that members of a research ethics committee, all investigators, post graduates should receive training in research ethics.

Table 3: Attitudes regarding research ethics.

\begin{tabular}{|c|c|c|c|c|c|c|c|c|c|c|c|c|}
\hline \multirow[t]{2}{*}{ SN } & \multirow[t]{2}{*}{$\begin{array}{l}\text { Aggregate } \\
(\%)\end{array}$} & \multicolumn{2}{|c|}{ Gender (\%) } & \multicolumn{3}{|c|}{ Academic position (\%) } & \multicolumn{2}{|c|}{$\begin{array}{l}\text { Prior training } \\
\text { in ethics }(\%)\end{array}$} & \multicolumn{4}{|c|}{ Number of publication (\%) } \\
\hline & & Male & Female & Professor & Associate & Assistant & Any & None & $\mathbf{0}$ & $1-2$ & $3-5$ & $>5$ \\
\hline 1 & 96 & 43.75 & 56.25 & 10.42 & 25 & 43.75 & 22.92 & 77 & 16.67 & 10.42 & 27.08 & 45.83 \\
\hline 2 & 80 & 40 & 60 & 12.50 & 25 & 62.50 & 22.5 & 77 & 17.50 & 12.50 & 27.50 & 42.50 \\
\hline 3 & 68 & 29.4 & $70.59 *$ & 14.71 & 20.59 & 64.71 & 23.53 & 76.47 & 17.65 & 14.71 & 29.41 & 38.24 \\
\hline 4 & 98 & 44.9 & 55.10 & 10.20 & 26.53 & 63.27 & 24.49 & 75.51 & 16.33 & 10.20 & 26.53 & 46.94 \\
\hline 5 & 100 & 44 & 56 & 12 & 26 & 62 & 24 & 76 & 16 & 10 & 26 & 48 \\
\hline 6 & 98 & 42.86 & 57.14 & 12.24 & 26.53 & 61.22 & 24.49 & 75.51 & 16.33 & 10.20 & 24.49 & 48.98 \\
\hline 7 & 90 & 40 & 60 & 11.11 & 28.89 & 60 & 20 & 80 & 17.78 & 11.11 & 26.67 & 44.44 \\
\hline
\end{tabular}

*p value $<0.05,1$. There is a need for a research ethics committee in each institution for ethical review of research, 2 . Ethical review of research by an EC is not necessary since there are scientific committees, 3. Ethical review of research by an EC would delay research and make it harder for the researcher, 4 . The members of a research ethics committee should receive training in research bioethics, 5. All investigators should have some training in research ethics, 6 . Research ethics should be taught as a mandatory postgraduate module, 7. Ethical review of research is only necessary for international collaborative research.

Table 4: Attitudes towards certain practices in the conduct of research.

\begin{tabular}{|lllllllllllll|}
\hline $\begin{array}{l}\text { AGGRE } \\
\text { gate(\%) }\end{array}$ & \multicolumn{3}{l}{ Gender $(\%)$} & \multicolumn{3}{c}{ Academic position(\%) } & \multicolumn{4}{c}{$\begin{array}{c}\text { Prior training } \\
\text { in ethics(\%) }\end{array}$} & \multicolumn{3}{c|}{ Number of publication(\%) } \\
\hline & Male & Female & Professor & Associate & Assistant & Any & None & 0 & $\mathbf{1 - 2}$ & $\mathbf{3 - 5}$ & $>\mathbf{5}$ \\
\hline 96 & 45.83 & 54.17 & 12.50 & 25 & 62.50 & 25 & 75 & 16.67 & 10.42 & 25 & 47.92 \\
\hline 84 & 40.48 & 59.52 & 11.90 & 23.81 & 69.05 & 26.19 & 73.81 & 19.05 & 11.90 & 28.57 & 40.48 \\
\hline 90 & 42.22 & 57.78 & 11.11 & 26.67 & 62.22 & 22.22 & 77.78 & 17.78 & 11.11 & 24.44 & 46.67 \\
\hline 100 & 44 & 56 & 12 & 26 & 62 & 24 & 76 & 16 & 10 & 26 & 48 \\
\hline 84 & 50 & 50 & 9.52 & 26.19 & 64.29 & 21.43 & 78.57 & 14.29 & 7.14 & 28.57 & 50 \\
\hline 88 & 56.82 & 43.18 & 11.36 & 27.27 & 61.36 & 22.7 & 77.27 & 15.91 & 6.82 & 27.27 & 50 \\
\hline 68 & 32.35 & $67.65^{*}$ & 14.71 & 20.59 & 64.71 & 26.47 & 73.53 & 14.71 & 11.76 & 23.53 & 50 \\
\hline
\end{tabular}

*p value $<0.05,1$. It is okay to fabricate data to improve outcome of research as long as there is no harms to the patients, 2 . No need to obtain research informed consent for blood samples obtained for clinical tests, 3. Patients should not be told about potential risks of a study because they may not enroll in the study, 4. Informed consent from patients is necessary for use of their biological samples in research, 5. Vulnerable groups such as children and the mentally ill could provide informed consent, 6 . Informed consent should always be obtained by having patients sign in a written form, 7. If no surrogate is available to give informed consent for vulnerable groups, they could still be included

Table 4 shows respondents attitudes towards certain practices in the conduct of research $96 \%$ believed that it is okay to fabricate data to improve outcome of research as long as there is no harms to the patients, $90 \%$ believed that patients should not be told about potential risks of a study because they may not enrol in the study $>80 \%$ believed that no need to obtain research informed consent for blood samples obtained for clinical tests, vulnerable groups such as children and the mentally ill could provide informed consent, informed consent should always be obtained by having patients sign in a written form, $100 \%$ believed that informed consent from patients is necessary for use of their biological samples in research and $68 \%$ taught that if no surrogate is available to give informed consent for vulnerable groups, they could still be included. Female faculty were significantly ( $p$ value 
$<0.05)$ more likely to believe that if no surrogate is available to give informed consent for vulnerable groups, they could still be included Table 4 also shows the association between research practice and demographic variables. Both men and women believed that vulnerable groups such as children and the mentally ill could provide informed consent. Male were more likely to believe that informed consent should always be obtained by having patients sign in a written form compared to female. Female faculty were more likely to believe that it is okay to fabricate data to improve outcome of research as long as there is no harms to the patients, no need to obtain research informed consent for blood samples obtained for clinical tests, patients should not be told about potential risks of a study because they may not enrol in the study, informed consent from patients is necessary for use of their biological samples in research, if no surrogate is available to give informed consent for vulnerable groups, they could still be included.

Assistant professor, faculty who had not undergone training and who had published $>5$ research papers were more likely to believe that it is okay to fabricate data to improve outcome of research as long as there is no harms to the patients, no need to obtain research informed consent for blood samples obtained for clinical tests, patients should not be told about potential risks of a study because they may not enrol in the study, informed consent from patients is necessary for use of their biological samples in research, vulnerable groups such as children and the mentally ill could provide informed consent, informed consent should always be obtained by having patients sign in a written form, if no surrogate is available to give informed consent for vulnerable groups, they still be included.

\section{DISCUSSION}

Table 1 shows the demographic data of the faculty, there were slightly more females $(56 \%)$ compared to male, assistant professors were more compared to associate professor and professor, $48 \%$ of participants had $>5$ publication, $76 \%$ had no prior training in research ethics.

Table 2 assess respondent's knowledge in research ethics Less than half of the respondents gave correct answers for question on guidelines in research ethics, while more than half of the respondents gave correct answer for other question on research knowledge.

Our study result is similar to study conducted by Kiran Kumar Mallela et al where $>50 \%$ of participants responded correctly for questions on informed consent, research involving children and institutional ethics committee and about 8-35\% participants had knowledge about various ethical guidelines. In a study by ElDessouky HF et al $12 \%$ gave correct answers for question on guidelines in research ethics. In contrast to study conducted by El-Dessouky $\mathrm{HF}$ et al where $<50 \%$ responded correctly, in our study $>50 \%$ of participants responded correctly for questions on role of a research ethics committee, confidentiality in medical research, research involving children. Our study result is similar to study conducted by Kiran Kumar Mallela et al where $>50 \%$ of participants responded correctly for questions on informed consent, research involving children and institutional ethics committee and about 8-35\% participants had knowledge about various ethical guidelines. ${ }^{5,10}$

Majority of Assistant professors, participants who had $>5$ publication and who had no prior training in research ethics responded correctly to all knowledge questions. This was in contrast to study conducted by El-Dessouky $\mathrm{HF}$ et al were majority of participants with prior training in research ethics responded correctly to knowledge questions.

For question on Composition of Institutional Ethics Committee female faculty significantly $(65 \%)$ ( $\mathrm{p}$ value $<0.005)$ responded correctly compared to male faculty $(35 \%)$.

Table 3 shows the respondent's attitudes to RECs and research ethics education. $96 \%$ of the respondents agreed there is a need for an REC in each institution. 80\% thought that the presence of scientific committees made the existence of an REC unnecessary this was in contrast to study by El-Dessouky $\mathrm{HF}$ et al where $10 \%$ of respondents thought that scientific committees made the existence of an REC unnecessary. 68\% thought that RECs would delay research and would make research harder to perform in contrast to study by El-Dessouky $\mathrm{HF}$ et al were $44 \%$ thought that RECs would delay research and in study conducted by Kiran Kumar Mallela et al 20\% had opinion that ethical committees would unnecessarily delay research. ${ }^{5,10}$ A large majority of the respondents (greater than 90\%) were in favour of research ethics education for postgraduates, investigators, and members of RECs, this was similar to previous studies. ${ }^{5,10} 90 \%$ believed that ethical review is only necessary for international collaborative research, in study by ElDessouky HF et al $<20 \%$ believed that ethical review is only necessary for international collaborative research.

Majority of Assistant professors, participants who had $>5$ publication and who had no prior training in research ethics agreed there is a need for an REC in each institution, the presence of scientific committees made the existence of an REC unnecessary, RECs would delay research and would make research harder to perform, were in favour of research ethics education for postgraduates, investigators, and members of RECs, and believed that ethical review is only necessary for international collaborative research. In study by ElDessouky HF et al Professors compared with the other faculty were significantly more likely to agree that ethical review of research is only necessary for international research, faculty "without any prior ethics training" were significantly more likely to think that an REC would be 
helpful (P <0.01). Furthermore, Mid- Level faculty and those with "prior ethics training" were significantly more likely to believe that an REC would delay research $(\mathrm{P}<$ $0.05)$

In our study female faculty significantly $(71 \%)$ (p value $<0.005$ ) believed RECs would delay research and would make research harder to perform compared to male faculty $(29 \%)$.

Table 4 shows the respondents attitudes toward several practices in research ethics. 96\% respondents thought it is okay to fabricate data to improve the outcome of the research if such an act did not cause harms to patients. Slightly more than $10 \%$ respondents thought it is okay to fabricate data to improve the outcome of the research if such an act did not cause harms to patients in study by ElDessouky HF et al. ${ }^{5}$ In previous study approximately $2 \%$ of respondents were willing to fabricate data. ${ }^{6,7} 84 \%$ responded that there is no need to obtain research informed consent for blood samples obtained for clinical tests similar results was seen in previous study. ${ }^{10} 90 \%$ believed that patients should not be told about potential risks of a study because they may not enroll in the study in contrast to $7 \%$ in study by El-Dessouky HF. ${ }^{5} 100 \%$ believed that Informed consent from patients is necessary for use of their biological samples in research in contrast to $87 \%$ in study by El-Dessouky HF, $84 \%$ believed that Vulnerable groups such as children and the mentally ill could provide informed consent in contrast to $39 \%$ in study by El-Dessouky HF and $46 \%$ in study conducted by Kiran Kumar Mallela et al. ${ }^{5,10}$ This result is made more significant by the findings of another study showing that research participants who participated in studies on oral health in Nigeria had poor understanding of several key elements of the informed consent process. ${ }^{9}$

$88 \%$ believed that Informed consent should always be obtained by having patients sign in a written form in contrast to $91 \%$ in study by El-Dessouky HF. ${ }^{5} 68 \%$ believed that If no surrogate is available to give informed consent for vulnerable groups, they could still be included in contrast to $7 \%$ in study by El-Dessouky $\mathrm{HF}^{5}$

Majority of Assistant professors, participants who had $>5$ publication and who had no prior training in research ethics agreed $84 \%$ responded that there is no need to obtain research informed consent for blood samples obtained for clinical test, patients should not be told about potential risks of a study because they may not enrol in the Informed consent from patients is necessary for use of their biological samples in research, Vulnerable groups such as children and the mentally ill could provide informed ,Informed consent should always be obtained by having patients sign in a written form. If no surrogate is available to give informed consent for vulnerable groups, they could still be included professors were more likely to agree that research performed on blood samples obtained for clinical purposes do not require informed consent compared with the other faculty. ${ }^{5}$ Asem and colleagues observed similar results regarding this issue among the faculty at Cairo University. ${ }^{8}$ In our study female faculty significantly $(68 \%)$ ( $p$ value $<0.005$ ) believed If no surrogate is available to give informed consent for vulnerable groups, they could still be included compared to male faculty $(32 \%)$.

\section{CONCLUSION}

Since majority of faculty were not trained in ethics. We therefore recommend further development of educational training in research ethics for all faculties, with special emphasis on vulnerable participants, responsible conduct of research, informed consent and the roles and functions of ECs.

\section{ACKNOWLEDGEMENTS}

Authors would like to thank the faculty members and Dean of ESIC-MC and PGIMSR, Bangalore for providing necessary research facilities.

\section{Funding: No funding sources \\ Conflict of interest: None declared \\ Ethical approval: The study was approved by the Institutional Ethics Committee}

\section{REFERENCES}

1. Normile D. The promise and pitfalls of clinical trials overseas, Science. 2008;322(5899):214-6.

2. World Health Organization. Declaration of HelsinkiEthical Principles for Medical Research Involving Human Subjects; 2008.

3. Council for International Organizations of Medical Sciences (CIOMS), International Ethical Guidelines for Biomedical Research Involving Human Subjects, Council for International Organizations of Medical Sciences, Geneva, Switzerland; 2002.

4. Muaz F. Family, patient and physician in medical decision making. Hastings Center Report. 2000;6:2837.

5. El-Dessouky HF, Abdel-Aziz AM, Ibrahim C, Moni M, Abul Fadl R, Silverman H. Knowledge, awareness, and attitudes about research ethics among dental faculty in the middle east: A pilot study. Int $\mathbf{J}$ Dent. 2011;2011:694759.

6. Eastwood S, Derish P, Leash E, Ordway S. Ethical issues in biomedical research: perceptions and practices of postdoctoral research fellows responding to a survey. Science and Engineering Ethics. 1996;2(1):89-114.

7. Fanelli D. How many scientists fabricate and falsify research? A systematic review and meta-analysis of survey data. PLoS ONE. 2009;4(5):5738.

8. Asem N, Silverman HJ. Perspectives of faculty at Cairo University towards research ethics and informed consent. In Proceedings of the Public Responsibility in Medicine and Research (PRIM and R ’06), Nashville, Tenn, USA; 2009. 
9. Taiwo OO, Kass N. Post-consent assessment of dental subjects' understanding of informed consent in oral health research in Nigeria, BMC Medical Ethics. 2009;10(1): 11 .

10. Mallela KK, Walia R, Devi TM, Das M, Sepolia S, Sethi P. Knowledge, Attitudes and Practice about Research Ethics among Dental Faculty in the North
India. Journal of International Oral Health. 2015;7(2):52-6.

Cite this article as: Munoli S, Niveditha G, Deepthi R. Knowledge, attitude and practice of research ethics among medical faculty in a teaching hospital. Int J Basic Clin Pharmacol 2017;6:913-8. 